\title{
Konvansiyonel Heaney tekniği ile on-basamak vajinal histerektomi tekniğinin karşılaştırılması
}

\section{Comparison of conventional Heaney's technique and ten-step vaginal hysterectomy technique}

\author{
Ümit GÖRKEM ${ }^{1}$, Cihan TOĞRUL', Hasan Ali INAL ${ }^{2}$, Tayfun GÜNGÖR ${ }^{1}$
}

'Hitit Üniversitesi, Tıp Fakültesi, Kadın Hastalıkları ve Doğum Anabilim Dalı, Çorum

${ }^{2}$ Konya Eğitim ve Araştırma Hastanesi, Kadın Hastalıkları ve Doğum Kliniği, Konya, TÜRKiYE

\section{ÖZET}

Amaç: Bu çalışmada vajinal histerektomi uygulanmış hastalarda Konvansiyonel Heaney tekniği ile On-Basamak Vajinal Histerektomi tekniğinin karşılaştııılması ve bu tekniklerin klinik sonuçlar üzerine etkisinin değerlendirilmesi amaçlanmıştır.

Gereç ve Yöntemler: Uterin prolapsus nedeniyle vajinal histerektomi yapılmış 49 hasta retrospektif olarak değerlendirildi. Bu hastaların 24'üne konvansiyonel Heaney tekniği, 25'ine ise yeni On-Basamak Vajinal Histerektomi tekniği uygulanmıştı. Her iki teknik, yaş, vücut kitle endeksi (BMI), gebelik sayısı, canlı doğum sayısı, ameliyat öncesi ve sonrası hemoglobin düzeyleri, ameliyat süresi, hastanede kalış süresi ve analjezik gereksinim süresi açısından karşılaştıııldı.

Bulgular: Ortalama yaş, BMI, gebelik sayısı, canlı doğum sayısı, ameliyat öncesi ve sonrası hemoglobin düzeyleri iki grupta da benzerdi $(P>0,05)$. On-Basamak Vajinal Histerektomi tekniği uygulanmış hastalarda ameliyat süresinin $(P=0,001)$, hastane kalış süresinin $(P=0,020)$ ve analjezik gereksinim süresinin $(P=0,006)$ daha kısa olduğu saptandı.

Sonuçlar: Ameliyat süresi, hastanede kalış süresi ve analjezik gereksinim günleri açısından On-Basamak Vajinal Histerektomi tekniğinin klinik sonuçları konvansiyonel Heaney tekniğine göre daha iyi olarak değerlendirilmiştir.

Anahtar kelimeler: Vajinal Histerektomi; Konvansiyonel Heaney Tekniği; On-Basamak Tekniği; Klinik Sonuçlar

Sorumlu Yazara: Dr. Ümit Görkem, Hitit Üniversitesi Tıp Fakültesi Kadın Hastalıkları ve Doğum Anabilim Dalı IVF Bölümü,

Corum, TURKEY

Phone:0090 5333479942 e-mail: drumitgorkem@hotmail.com

doi: $10.18663 /$ tjcl.98185

Bu makale 11-15 Mayıs 2015 tarihleri arasındaki Antalya'da gerçekleşen 13. Ulusal Jinekoloji ve Obstetrik (TJOD) Kongresinde poster olarak sunulmuştur. 


\section{ABSTRACT}

Aim: In this study, we aimed to compare conventional Heaney's method and the Ten-Step Vaginal Hysterectomy method and to analyse the effects of the both techniques on the clinical outcomes.

Material and Methods: Forty-nine patients who underwent vaginal hysterectomy with the diagnosis of uterine prolapses were retrospectively evaluated. Among them, 24 patients had underwent the conventional Heaney's method and 25 patients had underwent the Ten-Step Vaginal Hysterectomy method. The age, body mass index (BMI), number of pregnancies, number of live births, pre- and post-operative levels of haemoglobin, operation time, duration of hospitalization and analgesic requirement period were compared in both methods.

Results: The averages of ages, BMI, numbers of pregnancies, number of live births, pre- and post-operative haemoglobin levels were similar in both methods $(P>0.05)$. But the patients who underwent Ten-Step Vaginal Hysterectomy method had a significantly shorter operation time $(P=0.001)$, shorter hospital stay $(P=0.020)$ and shorter time of analgesics requirement $(P=0.006)$.

Conclusion: We concluded that in terms of operation time, hospital stay and analgesic requirement, the Ten-Step Vaginal Hysterectomy method had better clinical outcome than the conventional Heaney's method.

Key words: Vaginal Hysterectomy; Conventional Heaney's Method; Ten-Steps Method; Clinical Outcomes

\section{Giriş}

Vajinal histerektomi, abdominal histerektomiden yıllar önce M.Ö. 5. yüzyılda Hipokrat zamanında yapılmaya başlanmıştır. Illk vajinal histerektominin (VH) Langenberk tarafından 1813'de yapılmasından sonra Bellinger 1846'da ilk abdominal histerektomiyi (AH) gerçekleştirmiştir [1]. Bugüne kadar $\mathrm{AH}$ daha çok tercih edilirken son yıllarda ise laparoskopinin klinik kullanıma girmesi ile laparoskopi-asiste vajinal histerektomi (LAVH) popüler olmaya başlamıştır. Yapılan bir çalışmada VH ile LAVH arasında kan kaybı, komplikasyonlar, hastanede kalış süresi ve iyileşme süreci açısından bir fark bulunamamıştır [2].

Günümüzde histerektomi tipi seçilirken çabuk iyileşme, abdominal kesi olmaması ve daha kısa hastanede kalış süresi gibi nedenlerle vajinal yol tercih edilmektedir [3,4]. LAVH, VH'ye iyi bir alternatif değilken AH'ye göre ise iyi bir seçenektir [5]. Kanıta dayalı tıp açısından VH'nin, LAVH ve AH'ye göre daha iyi sonuçlara ve daha az komplikasyonlara sahip olduğunu gösteren birçok çalışma vardır [6-9]. VH için daha az kontraendikasyon söz konusu olup [10], VH operasyonu nulliparlara [11] ve büyük uteruslara da başarılı bir şekilde uygulanabilmektedir [12]. American College of Obstetricians and Gynecologists (ACOG)'un yeni görüşüne göre, nonkanseröz nedenler için uterusu almanın en güvenilir ve maliyeti en düşük yolu VH'dir [13].

Almanya'dan Michael Stark [4], daha önce tanımlanmış olan altı VH tekniğini tekrar gözden geçirip yeni bir yöntem ileri sürmüştür. Porges [14], Falk [15], von Theobald [16], Heaney [17], Joel-Cohen ve Chicago [18] yöntemlerinin ortak basamaklarını alıp gereksiz basamakları ise kullanımdan çıkararak "on-basamak vajinal histerektomi" diye adlandırdığı daha mantıklı, öğrenilmesi, uygulanması ve öğretilmesi kolay bir teknik geliştirmiş̧ir.
$\mathrm{Bu}$ çalışmada on-basamak vajinal histerektomi (OBVH) ile konvansiyonel Heaney vajinal histerektomi (HVH) tekniklerinin klinik sonuçlarının karşılaştııılması amaçlanmıştır.

\section{Gereç ve Yöntemler}

Bu çalışmada Mart 2005 ile Ocak 2015 tarihleri arasında Çorum Devlet Hastanesi Kadın Hastalıkları ve Doğum Kliniğinde uterin prolapsus tanısı ile aynı cerrah tarafından gerçekleştirilmiş toplam 52 adet vajinal histerektomi olgusu retrospektif olarak incelenmiştir. Çalışmamızın yerel etik kurul komitesi tarafından onayı alınmıştır (No: 2015/56). Geçirilmiş vajinal veya abdominal pelvik cerrahi öyküsü olanlar, prolapsusa eşlik eden diğer abdomino-pelvik bozuklukları olanlar, sistemik hastalığı olanlar, 12 haftadan büyük uterusu olanlar, endometrioması olanlar, pelvik enflamatuar hastalık öyküsü olanlar, serviks ve endometrium kanseri olanlar vajinal histerektomi endikasyonu kapsamı dışında düşünülmüştür. Bir adet intraoperatif rektal yaralanma, iki adet postoperatif hematom olmak üzere toplam üç hasta çalışma dışı bırakılmıştır. Çalışmaya dahil edilen toplam 49 olguya salpigo-ooferektomi yapılmaksızın vajinal histerektomi operasyonu uygulanmıştır. Uygulanan vajinal histerektomi tekniklerine göre hastalar iki gruba ayrılmıştır: Grup 1, konvansiyonel Heaney vajinal histerektomi (HVH) uygulanan 24 hastadan; grup 2, on-basamak vajinal histerektomi (OBVH) uygulanan 25 hastadan oluşmaktadır.

HVH tekniğinin basamakları, vajinal duvar ve serviks etrafına kesi yapılması, mesanenin uterustan ayrılması, anterior peritonun açılması, posterior peritonun açılması, uterosakral ligamentlerin kesilmesi ve bağlanması, kardinal ligamentlerin kesilmesi ve bağlanması, uterin damarların bağlanması, uterin fundusun dışarı doğru doğurtulması, tubo-ovarian round ligamentlerin kesilmesi ve bağlanması, cerrahi spesimenin çıkarılması, round ligament ve uterosakral-kardinal 
pedinküllerin vajinal mukozaya fiksasyonu, reperitonizasyon, anterior kolporafinin yapılması, vajinal mukozanın kapatılmasıdır [17].

OBVH tekniğinin basamakları, vajinal duvar ve serviks etrafına kesi yapılması, mesanenin uterustan ayrılması, posterior peritonun açılması, uterus alt bölümünün diseksiyonu, uterin damarların kesilip bağlanması, anterior peritonun açılması, uterus üst bölümünün diseksiyonu, peritonun açık bırakılması, pelvik tabanın tamiri, vajinal duvarın kapatılmasıdır [4].

Analjezik olarak hastalara postoperatif birinci günde intramüsküler diklofenak sodyum günde $2 \mathrm{kez}$, ardışık günlerde oral parasetemol $500 \mathrm{mg}$ günde $3 \mathrm{kez}$ verildi. Hastaların analjezik gereksinim olmadıklarını bildirmeleri ve klinik durumları dikkate alınarak hastaneden ayrılışları yapıldı.

Olguların yaşları, BMI, gebelik sayısı, canlı doğum sayısı, ameliyat öncesi ve ameliyat sonrası birinci gün hemoglobin (pre-op ve post-op $\mathrm{Hb}$ ) düzeyleri yanısıra operasyon süreleri, hastanede kalış süreleri ve analjezik kullanım süreleri istatistiksel olarak karşılaştıııldı.
Bu çalışmada SSPS (Statistical Package for Social Sciences) 15 programı kullanıldı. Normal veya anormal dağıım testi olarak Shapiro-Wilk testi uygulandı. Normal dağılımlı değişkenler bağımsız örneklem testi, anormal dağılım gösteren değişkenlere için ise Mann-Whitney $U$ testi yapıldı. Bulgular ortalama \pm standart sapma olarak verildi. Kategorik değişkenler için Fisher-Exact testi kullanıldı. İstatistiksel anlamlılık olarak $P$ değeri $<0,05$ olarak alındı.

\section{Bulgular}

Çalışmaya katılan HVH grubundaki 24 ve OBVH grubundaki 25 , toplam 49 hastanın retrospektif olarak istatistiksel analizi yapıldığında her iki grubun yaş ortalamaları, BMI, gebelik sayısı, canlı doğum sayısı, pre-op ve post-op $\mathrm{Hb}$ düzeyleri arasında bir fark görülmedi (sırayla $\mathrm{P}=0,382, \mathrm{P}=0,065, \mathrm{P}=0,311$, $\mathrm{P}=0,218, \mathrm{p}=0,634$ ve $\mathrm{P}=0,078$ ). Ancak $\mathrm{OBVH}$ tekniği ile opere edilen hastalarda daha kısa operasyon süresi $(50,80 \pm 12,88$ dakika / 97,92 $\pm 18,70$ dakika, $P=0,001)$, daha az hastanede kalış süresi $(3,44 \pm 1,22$ gün / 4,00 $\pm 0,97$ gün, $P=0,020)$ ve daha az analjezik gereksinim günü $(3,32 \pm 0,94$ gün / 4,04 \pm 0,95 gün, $P=0,006$ ) tespit edildi. (Tablo 1 ).

Tablo 1. Konvansiyonel Heaney vajinal histerektomi tekniği ile on-basamak vajinal histerektomi tekniklerinin karşılaştırılması.

\begin{tabular}{|l|c|c|c|}
\hline & HVH $(\mathrm{n}=24)$ & OBVH $(\mathrm{n}=25)$ & $\mathrm{P}$ \\
\hline Yaş (yıl) & $61,21 \pm 9,72$ & $58,96 \pm 8,07$ & 0,382 \\
\hline BMI (kg/m2) & $28,67 \pm 3,37$ & $29,74 \pm 2,88$ & 0,065 \\
\hline Gebelik sayısı & $3,87 \pm 1,26$ & $4,24 \pm 1,23$ & 0,311 \\
\hline Canlı doğum sayısı & $2,20 \pm 1,06$ & $2,56 \pm 0,86$ & 0,218 \\
\hline Hastanede kalış süresi (gün) & $4,00 \pm 0,97$ & $3,44 \pm 1,22$ & $0,020^{*}$ \\
\hline Operasyon süresi (dakika) & $97,92 \pm 18,70$ & $50,80 \pm 12,88$ & $0,001^{*}$ \\
\hline Ameliyat öncesi Hb (g/dL) & $13,37 \pm 1,24$ & $13,20 \pm 1,24$ & 0,634 \\
\hline Ameliyat sonrası Hb (g/dL) & $10,52 \pm 0,61$ & $10,85 \pm 0,65$ & 0,078 \\
\hline Analjezik gereksinim süresi (gün) & $4,04 \pm 0,95$ & $3,32 \pm 0,94$ & $0,006^{*}$ \\
\hline
\end{tabular}

KIsaltmalar: HVH; Heaney Vajinal Histerektomi, OBVH; On-Basamak Vajinal Histerektomi

${ }^{*} P<0,05$ istatistiksel olarak anlamlı.

\section{Tartışma}

Cerrahi teknikler açısından geleneksellik, bazen yeni düşünceler ve gelişimlere engel olarak bazen de bir tabu olarak karşımıza çıkabilmektedir. Dolayısı ile cerrahi tekniklerdeki yeni gelişimler için anatomik ve fizyolojik açıdan düşünceler gözden geçirilmelidir. Jinekolojik cerrahlar tarafından sıklıkla uygulanan VH birçok basamaktan oluşmaktadır. Bu basamakların çeşitliği ve tercih edilme nedenlerinde de farklııklar gözlenmektedir.

Her iki vajinal histerektomi tekniğinin basamakları karşılaştıııldığında bazı önemli farklar görülmektedir. HVH tekniğinde vajinal mukozaya ilk önce ters $T$ kesisi yapılıp hemen ardından ön periton açılmaktadır. OBVH tekniğinde ise ilk olarak vajinal duvar ve serviks etrafına kesi yapılarak vajinal duvar neredeyse kansız, daha kolay ve kısa sürede ayrılmaktadır. Bu şekilde vajinal duvar anterior kolporafi için hazır olmaktadır [4]. Mesanenin uterustan ayrılma aşamasında anterior peritonun açılma işleminin önce yapılması hem gereksizdir hem de önerilmemektedir. Çünkü mesane zedelenmeleri çoğu bu basamakta olmaktadır [4]. Bizim çalışmamızda da her iki grupta için hiçbir mesane zedelenmesi görülmemiştir.

OBVH'nin uterus alt bölümünün diseksiyonu olan dördüncü basamağında sakro-uterin ligament ve paraservikal dokular tek bir manevra ile tutularak bağlanmaktadır. HVH tekniğindeki her iki sakro-uterin ligamentlerin ayrı birer basamak olarak kesilmesi zaman kaybettiren faydasız bir işlemdir $[4,19]$. Bunun sayesinde çalışmamızda ise $\mathrm{OBVH}$ için operasyon süresi $\mathrm{HVH}$ tekniğindeki operasyon süresine göre daha kısadır. 
OBVH tekniğinin altıncı basamağıolanön peritonun açılmasının bu evrede yapılması, ön peritonun anatomik yakınlıklarının tam tanımlanamadığı geçirilmiş sezeryan doğum ve pelvik cerrahi öyküsü olanlarda mesanenin güvenliği için önem arz etmektedir [4].

OBVH'nin sekizinci basamağı olan peritonun açık bırakılması birçok avantaj sağlamaktadır. 1980'de Harold Ellis [20] abdominal cerrahi sonrası peritonun kapatılmasının gereksiz olduğunu göstermiştir. Cilt ve diğer doku kesilerinin aksine ince periton kenarlarının sütür yardımıyla bir araya getirilmesi daha iyi bir iyileşme sağlamamaktadır. Hatta periton sütürleri kanlamada bozulmaya ve yapışıklıklara bile neden olabilmektedir. Periton açık bırakıldığında ise çölemik hücreleri kısa sürede yeni bir periton oluşturduğu için daha az yapışıklık görülmektedir [4]. Ayrıca peritonun açık bırakılmasının bağırsak fonksiyonları üzerine de yararlı etkileri vardır [21-23].

OBVH'nin dokuzuncu basamağında her iki sakro-uterin ligamentler ve paraservikal dokular cul-de-sac obliterasyonu amacıyla birbirlerine bağlanmaktadır [4,24]. Böylece postoperatif süreçte enterosel gelişimi riski azalmaktadır. Ayrıca OBVH tekniğinin onuncu basamağındaki "vajinal cuff" In bir bütün olarak kapatılması da birçok avantaj getirmektedir [23]. Böylece sadece anatomik değişiklikler değil fizyolojik değişimler de dikkate alınmış olunmaktadır. Bizim çalışmamızda da uygulanmış olan tüm bu OBVH tekniğinin avantajları ile daha kısa operasyon süresi ve hastanede kalış süresi ile daha az ağrı kesici kullanım süresi görülmüştür.

OBVH tekniğinin üstün olduğunu gösteren Bina ve ark. [25] yapmış olduğu güncel bir çalışmada çalışmamıza benzer sonuçlar bildirilmiştir. Bu çalışmada yaşları 42-72 olan uterin prolapsusları olan hastalara uygulanan $\mathrm{HVH}$ ve OBVH teknikleri karşılaştırılmıştır. OBVH tekniğinde daha kısa operasyon süresi, daha kısa analjezik gereksinim süresi saptanmıştır. Hastanede kalış süreleri her iki grupta aynı olduğu görülmüştür. Bizim çalışmamızda ise hastanede kalış sürelerinin de $\mathrm{OBVH}$ grubunda daha kısa olduğu bulunmuştur.

Çalışmamızın ön önemli kısıtlılığı randomize prospektif planlanmamış olmasıdır. Diğer bir kısıtılık ise operasyon sonrası ağrı kesici kullanım süresinin değerlendirilmesinin kantitatif bir yöntemle yapılmamasıdır. Ayrıca çalışmamızda her iki grup için, preoperatif ve postoperatif, kısa veya uzun dönemde prolapsusun dereceleri karşılaştırılamamıştır.

\section{Sonuç}

OBVH tekniği geleneksel HVH tekniğine göre daha basit, daha uygulanabilir ve klinik sonuçları daha üstün olabilecek bir tekniktir. Bu teknik ameliyat sürelerinin kısalmasına dolayısı ile ameliyat salonlarının daha verimli kullanılmasını sağlayabilecektir. Hastanede yatış süreleri daha kısa olduğundan servis hasta yatakları da verimli kullanılabilecektir. Ayrıca kısa hastanede kalış süreleri, hastane enfeksiyonları açısından avantaj doğurmaktadır. Hastalar ise ağrı için daha kısa süreli analjezik kullanacaklardır. Uzun dönem etkilerinin takibi ve tekniğin standardize olup yaygınlaşması için ölçülebilir verilerle zenginleştirilmiş randomize prospektif çalışmalara gereksinim vardır.

Maddi Destek ve Çıkar illişkisi: Çalışmayı maddi olarak destekleyen kişi/kuruluş yoktur ve yazarların herhangi bir çıkara dayalı ilişkisi yoktur.

\section{Kaynaklar}

1. John A R, John D T, Te Linde's Operative Gynaecology:Edition Lippincott-Raven Publishers: Philadelphia-Newyork: 1997; 33;771-5

2. Summitt Jr RL, Stovall TG, Lipscomb GH, Ling FW. Randomized comparison of laparoscopy-assisted vaginal hysterectomy with standard vaginal hysterectomy in an outpatient setting. Obstet Gynecol 1992; 80: 895-901.

3. Kalogirou D, Antoniou G, Zioris C, Fotopoulos S, Karakitsos P. Vaginal hysterectomy: technique and results in the last twenty years. J Gynecol Surg 1995; 11: 201-7.

4. Stark M, Gerli S, Di Renzo GC. An example for an optimized technique: the ten-step vaginal hysterectomy. Progress in Obstetric and Gyanecology 2006; 17: 358-68.

5. Claerhout F, Deprest J. Laparoscopic hysterectomy for benign diseases. Best Pract Res Clin Obstet Gynaecol 2005; 19: 357-75.

6. Campbell ES, Xiao H, Smith MK. Types of hysterectomy. Comparison of characteristic, hospital costs, utilization and outcomes. J Repond Med 2003; 48: 943-9.

7. Drahonovsky J, Haakova L, Otcenasek M, Krofta L, Kucera E, Feyereisl J. A prospective randomized comparison of vaginal hysterectomy, laparoscopically assisted vaginal hysterectomy and total laparoscopic hysterectomy in women with benign uterine disease. Eur J Obstet Gynecol Reprod Biol. 2010; 148: 172-6. 
8. American College of Obstetricians and Gynecologists: Appropriate use of laparoscopically assisted vaginal hysterectomy. Obstet Gynecol 2005; 105: 929-30.

9. Meikle SF, Nugent EW, Orleans M. Complications and recovery from laparoscopy assisted vaginal hysterectomy compared with abdominal and vaginal hysterectomy. Obstet Gynecol 1997; 89: 304-11.

10. Doucette RC, Sharp HT, Alder SC. Challenging generally accepted contraindications to vaginal hysterectomy. Am J Obstet Gynecol 2001; 184: 1386-9.

11. Dhainaut $C$, Salomon LJ, Junger $M$, Marcollet $A$, Madelenat $P$. Hysterectomies in patients with no history of vaginal delivery. $A$ study of 243 cases. Gynecol Obstet Fertil 2005; 33: 11-6.

12. Li Z, Leng J, Lang J, Tang J. Vaginal hysterectomy for patients with moderately enlarged uterus of benign lesions. Chin Med Sci J 2004; 19: 60-3.

13. The American College of Obstetricians and Gynecologists (ACOG) Abdominal or laparoscopically assisted vaginal hysterectomy. ACOG Recommends Vaginal Hysterectomy November issue of Obstetrics \& Gynecology, 22.10.09.

14. Paldi E, Fimar S, Naiger R, Weisseman A, Feldman EJ. Vaginal hysterectomy using the Porges method. Report on 100 cases. J Gynecol Obster Biol Reprod 1988; 17: 233-6.

15. Falk HC, Soichet $\mathrm{S}$. The technique of vaginal hysterectomy, Clin Obstet Gynecol 1972; 15: 703-54.

16. Von Theobald P. Simplified vaginal hysterectomy. J Chir 2001;138: 93-8.

17. Kalogirou D, Antoniou G, Zioris C, Folopoulos S, Karakitsos P. Vaginal hysterectomy: technique and results in the last twenty years. J Gynecol Surg 1995; 11: 201-7.
18. Lash AF, Stepto RC. Chicago technique for vaginal hysterectomy at the Cook County Hospital. Clin Obstet Gynecol 1972; 15: 755-68.

19. Kudo R, Yamauchi O, Okazaki T, Sagae S, Ito E, Hashimoto M. Vaginal hysterectomy without ligation of the ligaments of the cervix uteri. Surg Gynecol Obstet 1990; 170: 299-305.

20. Ellis $H$. Internal overhealing: the problem of intraperitoneal adhesions. World J Surg 1980; 4: 303-6.

21. Stark M. Clinical evidence that suturing the peritoneum after laparotomy is unnecessary for healing. World J Surg 1993; 17: 419.

22. Janschek EC, Hohlagschwandtner M, Nather A, Schindl M, Joura EA. A study of nonclosure of the peritoneum at vaginal hysterectomy. Arch Gynecol Obstet 2003; 267: 213-6.

23. Miskry T, Magos A. Mass closure: a new technique for closure of the vaginal vault at vaginal hysterectomy. $\mathrm{Br} J$ Obstet Gynaecol 2001; 108: 1295-7.

24. Heaney NS. Vaginal hysterectomy-its indications and technique. Am J Surg 1940; 56: 284-8.

25. Bina I, Akhter D. The ten-step vaginal hysterectomy-a newer and beter approach. J Bangladesh Coll Phys Surg 2012; 30: 71-7. 